\title{
Facts and Fantasies about Gold
}

\author{
Joachim Klement ${ }^{1}$
}

\begin{abstract}
Due to the increasing popularity of gold as an investment the demand for effective risk management techniques for gold investments has increased as well. In this paper we analyze several drivers of the price of gold that have been proposed in the past. Our analysis indicates that short-term volatility of the price of gold remains rather unpredictable with many of the explanations like the fund flows in physical gold ETF either unreliable or unstable over time. Our analysis suggests that there is a stable non-linear relationship between the price of gold and changes in inflation rates or real interest rates that might be exploited for risk management purposes.
\end{abstract}

JEL classification numbers: G12

Keywords: Gold, Inflation, Real Interest Rates, VIX, US Dollar, ETF Fund Flows

\section{Introduction}

After twelve consecutive calendar years of positive returns, gold has increasingly caught the attention of investors globally. However, as the events of 2013 showed dramatically, the downside risks of gold can be significant both in the short term as well as in the long term. In April 2013 the price of gold declined by 13.6\% in two trading days while the price of gold declined by roughly $86 \%$ in its secular bear market between 1980 and 1999 . Thus, risk managers and portfolio managers need to be able to monitor and control the risks of an existing or prospective gold investment. However, gold as an investment poses some significant challenges. Just like other commodity investments gold does not generate cash flows and thus traditional methods to assess fair values of gold like discounted cash flow models cannot be applied to gold. Similarly, the sensitivity to gold to changing cash flows cannot be assessed and thus many traditional risk management approaches are not applicable to gold investments.

It is possible to assess risks and opportunities for gold investments through an analysis of the fundamental demand and supply for the metal, but these fundamental drivers of the price of gold are typically very slow moving and stable over time. The price of gold, however, is far more volatile both in the short run as well as the long run than the

\footnotetext{
${ }^{1}$ Wellershoff \& Partners Ltd. e-mail: Joachim.klement@wellershoff.ch

Article Info: Received: July 28, 2014. Revised: September 1, 2014

Published online : December 30, 2014
} 
fundamentals so that risk managers need to find ways to assess risks based on this excess volatility.

In this overview article we assess several factors that have been used to explain changes in the price of gold. These factors range from more fundamental ones like the marginal cost of production to the more behavioral ones like the flows in and out of physical gold ETF. We assess viability of these factors in turn and their usefulness for risk management. We start by addressing the most commonly cited

\section{Literature Review}

Gold has mostly been considered as a safe haven asset and inflation hedge in the literature. Abdullah (2013) and Jastram (1977) show that gold has acted as an effective store of value and inflation hedge both in the United Kingdom and the United States since the middle ages. However, with the end of the Bretton Woods system of fixed exchange rates gold prices have not been linked to the US Dollar anymore. Erb and Harvey (2013) have recently investigated the correlation between changes in the price of gold and unexpected inflation and found that in normal times gold does not provide a good hedge against unexpected inflation.

On the other hand gold has acted as a safe haven asset in times of financial crisis, political unrest and increased economic turmoil. Baur and Lucey (2010) and Baur and McDermott (2010) have shown that this aspect of gold does lead to low or even negative correlations between the metal and other financial assets like stocks or bonds. Even though this safe haven characteristic of gold may have weakened recently (Baur and Clover [5]) it seems to be statistically and economically viable.

Previous studies have mostly focused on the diversification benefits of gold relative to more traditional assets such as stocks and bonds. In this analysis we want to focus more on the drivers of the price of gold as a means to manage risks in a gold investment. Unfortunately, while many drivers of the price of gold have been suggested in the media and by analysts recently, very few of them have been empirically investigated. We start our investigation by looking at the link between gold and inflation - a link that has been established in previous literature but may have weakened after the end of the Bretton Woods system of fixed exchange rates.

\section{Main Results}

\subsection{Gold as an Inflation Hedge and Store of Value}

Gold as a store of value has a history that goes back hundreds of years. The real price of gold has been remarkably stable over most of these times indicating that gold provided an inflation hedge at least for most of the time (Abdullah, 2013; Jastram, 1977). However, there have been prolonged episodes that can last decades when the real value of gold declines. The last of these episodes happened after the gold crash in 1982 when the price of gold declined in real terms until 1999. Since then however, the real price of gold has risen dramatically. But holding gold as an inflation hedge should work not only over time periods like decades. In order to provide a meaningful investment proposition there 
should be a reliable relationship between changes in the price of gold and changes or levels of inflation expectations.

Figure 1 shows the change in inflation in percentage points (based on the United States all-urban CPI index) together with the change in the price of gold over rolling 12-month periods. We used monthly data since January 1970 for both the price of gold as well as inflation.

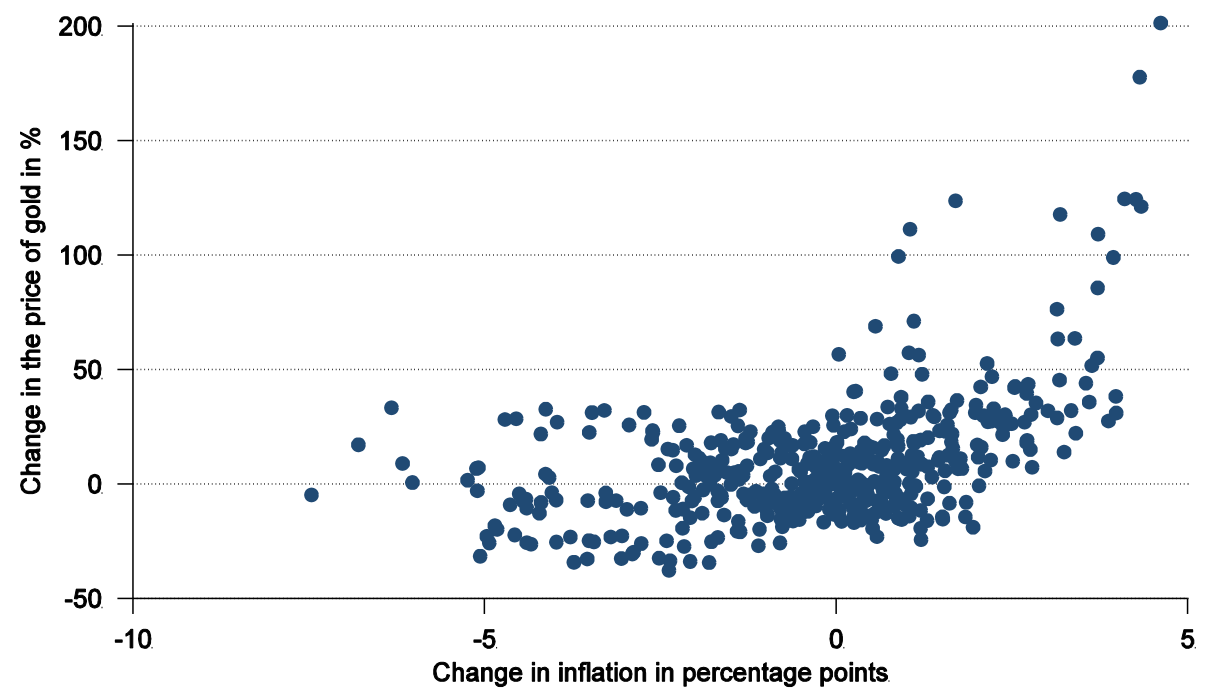

Figure 1: Change in inflation and change in the price of gold Source: Thomson Financial Datastream

The relationship between the change in inflation and the change in the price of gold is clearly non-linear. Rising gold prices tend to coincide with periods of rising inflation. This relationship becomes particularly strong when inflation rises strongly (i.e. more than about 2 percentage points within 12 months). On the other hand declining inflation tends to coincide with a drop in the price of gold. Looking at the variation of this relationship over time (not shown here) we also find that in times of disinflation like the 1980s and 1990s the relationship between the price of gold and inflation tends to be much weaker than in times of increasing inflation (e.g. the 1970s and the last decade).

In order to test the power of gold as an inflation hedge in practice we have performed a $\chi 2$-test on the hypothesis that the price of gold rises when inflation increases and vice versa. The $\chi^{2}$-test is the simplest way to test a hypothesis for statistical significance without assuming any specific relationship between the change in the price of gold and the change in inflation. Thus, the test is especially suited for non-linear relationships like the one we observe here.

Table 1 below counts the number of incidences when rising (falling) inflation coincided with rising (falling) prices of gold during the last 40 years. Incidents where the postulated relationship holds are marked in white. Incidents when the relationship between gold and inflation was violated are marked in grey. 
Table 1: Relationship between change in inflation and the price of gold

\begin{tabular}{lcc|} 
& Inflation rises & Inflation falls \\
Gold price rises & 163 & 108 \\
Gold price falls & 71 & 125 \\
\hline
\end{tabular}

The resulting $\chi^{2}$-statistics is 26.04 which is highly statistically significant. In other words over the last forty years there has been a reliable relationship between changes in inflation expectations and changes in the price of gold. We have also tested the relationship between the level of inflation at the beginning of each month and the subsequent twelve-month change in the price of gold. Again we found a significant result that showed that high inflation (meaning inflation rates of $4 \%$ or more) is typically followed by rising prices in gold during the subsequent year. Both relationships prove robust not only when tested since 1970 but also over the last ten or the last five years since the end of the financial crisis.

Overall then, we conclude that there is a reliable coincident relationship between the price of gold and inflation rates. The main problem for risk managers, however, is the difficulty to use this relationship in practical applications. Inflation is notoriously hard to predict even for central banks whose primary job is to gear monetary policy towards price stability. But our results suggest that there are at least qualitative and regime based ways to tackle this problem. First, note that for changes in inflation rates above 2 percentage points it becomes very unlikely to see declining gold prices while for changes in inflation rates below this mark the change in gold price is roughly normally distributed around the random walk. This allows a risk manager to model potential market risks in gold holdings in a two-regime approach. Regime switching models can then be used to assess the probability of switching from one regime to another based on the probability of the expected change in inflation rates.

\subsection{Gold and Real Interest Rates}

Gold competes with fixed income investments for investor liquidity. If real interest rates rise or are high, the opportunity costs of gold relative to fixed income investments rises and the demand for gold drops. But real interest rates plus inflation expectations sum up to nominal interest rates. Thus, real rates might change due to an expected change in inflation when nominal interest rates remain stable. Particularly during the era of financial repression 1940 to 1980 and again since the end of the financial crisis 2009 central banks in the United States and other countries have been trying to actively influence long-term nominal interest rates and keep them at artificially low levels to stimulate economic activity. Thus, real rates might fall not because the economic outlook deteriorates but because inflation expectations and subsequent realized inflation rise while nominal interest rates are kept stable.

Thus, when we look at Figure 2 the observable relationship should not be over-interpreted. We calculated the change in real interest rates based as the change in 1-year nominal interest rates for US Treasury securities minus the change in inflation over the same time period. There is a clear statistically significant relationship between changes in real interest rates and changes in the price of gold over the last 40 years. If real interest rates decline this decline is reflected by increasing prices of gold and vice versa. We tested this 
relationship also for shorter time periods like ten-year and five-year periods and found that it is stable over time and still holds in the post-crisis market we live in. Again the relationship is non-linear and skewed, meaning that declining real interest rates typically coincide with bigger rallies in the price of gold than rising real rates and a decline in the price of gold.

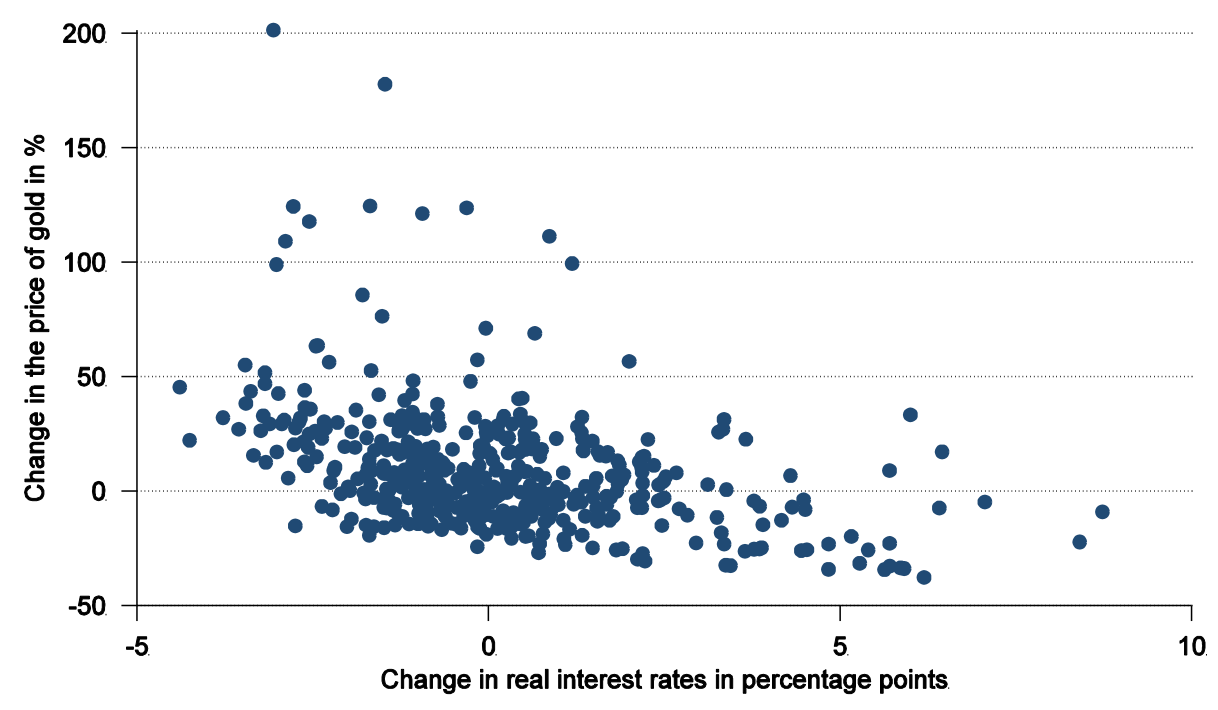

Figure 2: Change in real interest rates and change in the price of gold Source: Thomson Financial Datastream

Similarly we looked at the relationship between the level of real interest rates and subsequent 12-month changes in the price of gold and found again a statistically significant relationship between the two that remained stable over the last years. A high level of real interest rates is typically followed by negative changes in the price of gold while negative or low levels of real interest rates are typically followed by a rally in gold. However, in practice we cannot know what caused real interest rates to change. It might be that real interest rates directly influence the price of gold, but it might also be that both the price of gold and real interest rates are influenced by a common factor like changes in inflation expectations or fears of tail events and crisis. In other words, the correlation observed here does not imply any causation.

\subsection{Gold as a Crisis Hedge}

No matter which time we live in, gold has been touted as the ultimate crisis hedge for decades. One would expect that in times when political or economic uncertainty is rising, equity markets should drop while gold prices should rise. Baur and Lucey (2010) and Baur and McDermott (2010) have investigated the behavior of gold in times of equity market crisis extensively and found that gold historically provided a crisis hedge due to its low correlation in most market environments and its increasingly negative correlation with most global equity markets during times of extreme equity market distress. However, as gold has become more popular as an investment to protect against equity market 
declines this characteristic as a crisis hedge might have become less pronounced. As Baur and Glover (2012) show based on both theoretical and empirical arguments, investors who hold significant amounts of gold in their portfolios may be forced to sell parts or all of these holdings in times of equity market stress if they face borrowing or liquidity constraints in their other portfolio holdings. As a result a decline in equity markets can lead to contagion in gold markets if a sufficient number of investors hold significant amounts of gold in their portfolios. This leads to increased co movement between gold and equity markets.

Figure 3 shows the VIX Volatility index as a typical gauge of investor fear in equity markets together with the price of gold. It is obvious that there is no long-term correlation between gold and the VIX. Similarly we have tested the correlation between gold and the VIX over shorter time frames like days, weeks or months as well and found correlations close to zero. In times of extreme market stress as evidenced by the most extreme spikes in the VIX index gold prices tend to increase as well. However, during the financial crisis 2008 gold prices declined significantly even though equity markets were under severe stress. It stands to reason that this decline in gold prices has been triggered in part by forced selling of financial investors rather than actual changes in supply and demand, inflation or real interest rates.

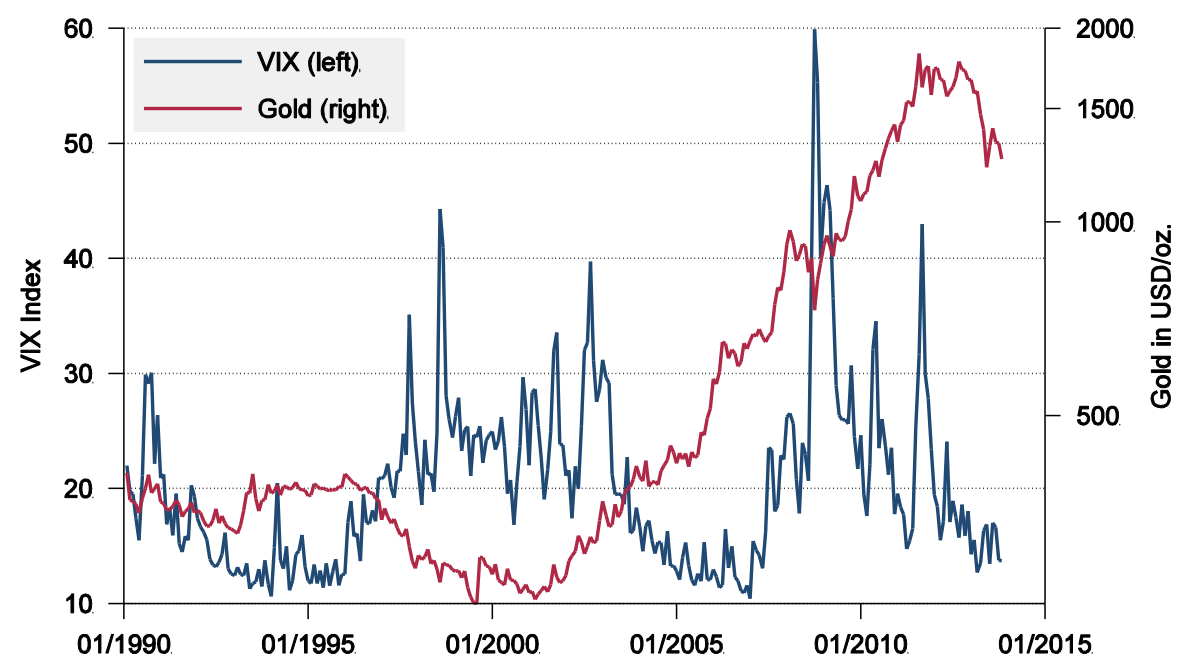

Figure 3: VIX and the price of gold since 1990

Source: Thomson Financial Datastream

\subsection{Gold and the US Dollar}

It is often argued that gold provides a hedge against currency debasement. If inflation in the United States is higher than in Switzerland for example, the US Dollar should over time depreciate against the Swiss Franc. The price of gold since it is denominated in US Dollars should at least partially hedge against this currency depreciation since through its inflation hedging properties. Similarly if the US Dollar is devalued against other currencies through other forms of debasement (e.g. currency reform or change of a fixed 
exchange rate) gold as safe haven asset should partially protect against this debasement as well. Unfortunately, the empirical evidence for this theory is rather weak. If gold were effectively a protection against a devaluation or debasement of the US Dollar the price of gold expressed in a safe haven currency like the Swiss Franc should be much less volatile than the price of gold expressed in US Dollars. But the annualized volatility of gold expressed in Swiss Francs between 1970 and 2013 is 20.2\% compared to $21.2 \%$ when the price of gold is expressed in US Dollars.

The theory is further weakened when one looks at correlations between the changes in the price of gold and changes in exchange rates for different currencies vs. the US Dollar in Figure 4 taken from Erband Harvey (2013). While there is a negative correlation between the price of gold and exchange rate movement for all the currencies shown here, the correlation is rather small. Changes in exchange rates can typically explain less than $10 \%$ of the variation in the price of gold. Risk managers should thus be wary of the relationship between gold and exchange rates as a significant influence in the behavior of gold prices.

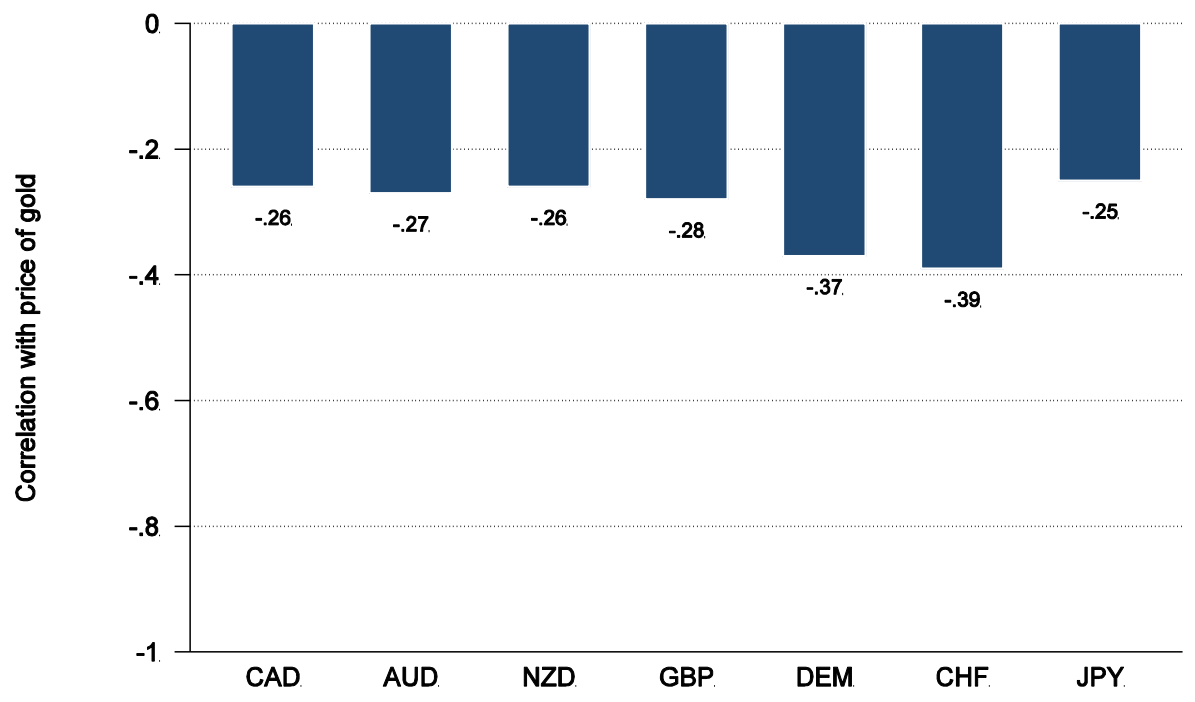

Figure 4: Correlation between exchange rates and the price of gold (1975-2012) Source: Erb and Harvey (2013)

\subsection{Gold and Production Costs}

Economic theory states that the price of gold should at least be as high as the marginal costs of production of gold. Otherwise production will be curtailed and the resulting supply shortage leads to rising prices. While there is an intuitive logic behind this argument it is often used in the wrong way. Many investors and analysts compare the average production cost of an ounce of gold and conclude that since the average price of gold is significantly above the average price of gold, gold is overvalued. The flaw in this argument is that the average cost of production of an ounce of gold is not what should determine the price of gold. It is the marginal cost of production (i.e. the cost of production of the last ounce of gold sold in the market) that puts a floor under the price of 
gold. If the price of gold drops below this marginal cost of production for a sufficiently long time, some loss making production facilities will close and gold supply will decline. The result should be either a rising price of gold until these production facilities can operate profitably again or inefficient production is replaced with more cost efficient methods.

Research by Korda Mentha (2013) shows indeed that after 1974 when the gold price was allowed to float relative to the US Dollar until about 2000 the price of gold was indeed at least as high as the sustainable cost of production. But even then there were prolonged periods (e.g. from 1977 to 1983 and again from 1987 to 1991) when the price of gold was significantly higher than the marginal cost of production. Figure 5 shows the premium of the average price of gold and the marginal cost of production since 2000. It is obvious that during the last 13 years the marginal cost of production has acted as a floor for the price of gold that was touched at the beginning of the new millennium and then again around 2004 and 2005. All the other years, until 2013 show a significant premium of the price of gold relative to the marginal cost of production. This relationship can be exploited for risk management purposes because the difference between the current market price of gold and the marginal cost of production provides a limit for the potential drawdown risk of gold over the long term.

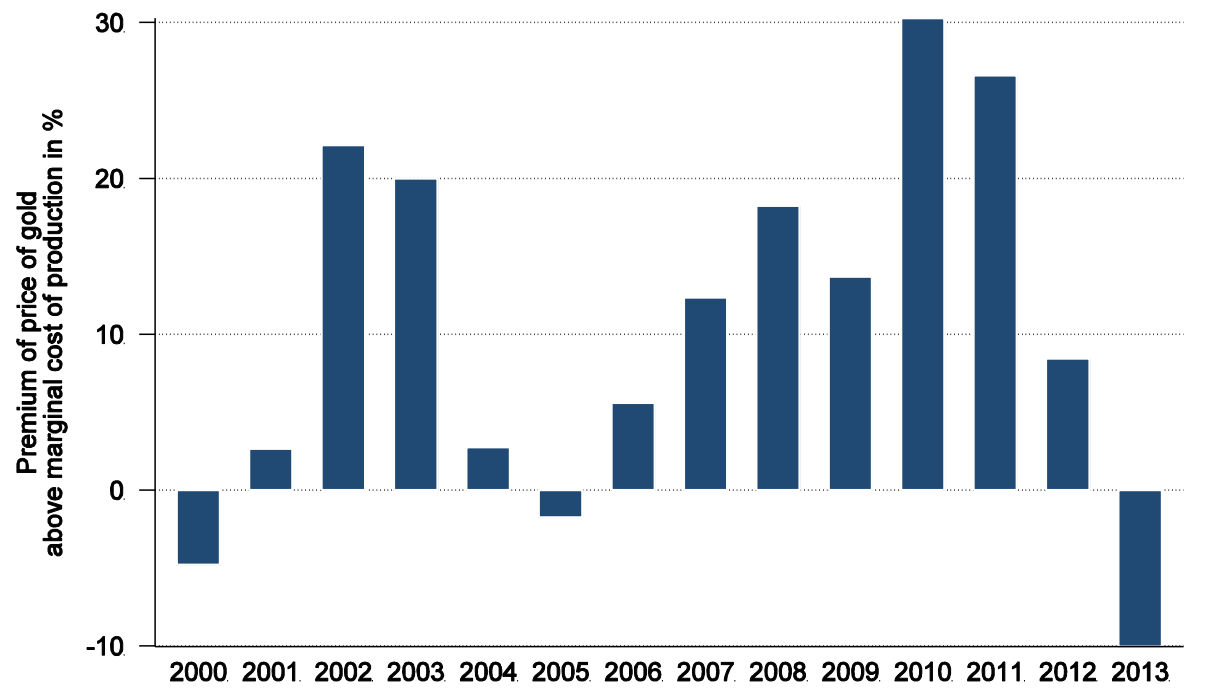

Figure 5: Premium of average price of gold relative to marginal cost of production Source: Thomson Financial Data stream, Earth Res source Investment Group

\subsection{Gold and ETF Holdings}

Particularly during the severe decline of gold prices in 2013 many analysts have argued that investors selling physical gold ETF lead to price pressure. Alternatively, increased demand by ETF investors should support gold prices. This theory is typically corroborated by the seemingly simultaneous decline in gold prices and ETF holdings throughout the year 2013 .

While investment demand by physical gold ETFs and similar investment vehicles is very 
volatile, the demand over the last five years was just about $5 \%$ of total demand for gold. More than $80 \%$ of global demand stems from the demand for gold bars and coins and jewelry. It seems unlikely that such a small part of the total demand could lead to price swings in the magnitude of $20 \%$ or more. In Figure 6 we have adopted a wider view of the link between ETF holdings and the price of gold. The figure shows the price of gold together with the holdings of the two largest physical gold ETFs in the world (the SPDR Gold Trust and the ZKB Physical Gold ETF in Switzerland). There are other similar products available by now but the amount of gold they hold is much smaller than any of the two ETFs and their holdings are typically highly correlated with the holdings of the two big ETFs. Visual inspection of the chart alone shows that the current co-movement of ETF holdings and the price of gold exists only since the end of 2012. Before this time there has been practically no correlation between ETF holdings and the price of gold. We have calculated the correlation between ETF holdings and the price of gold on investment horizons of one day up to one year and found a correlation of just +0.2 to +0.4 .

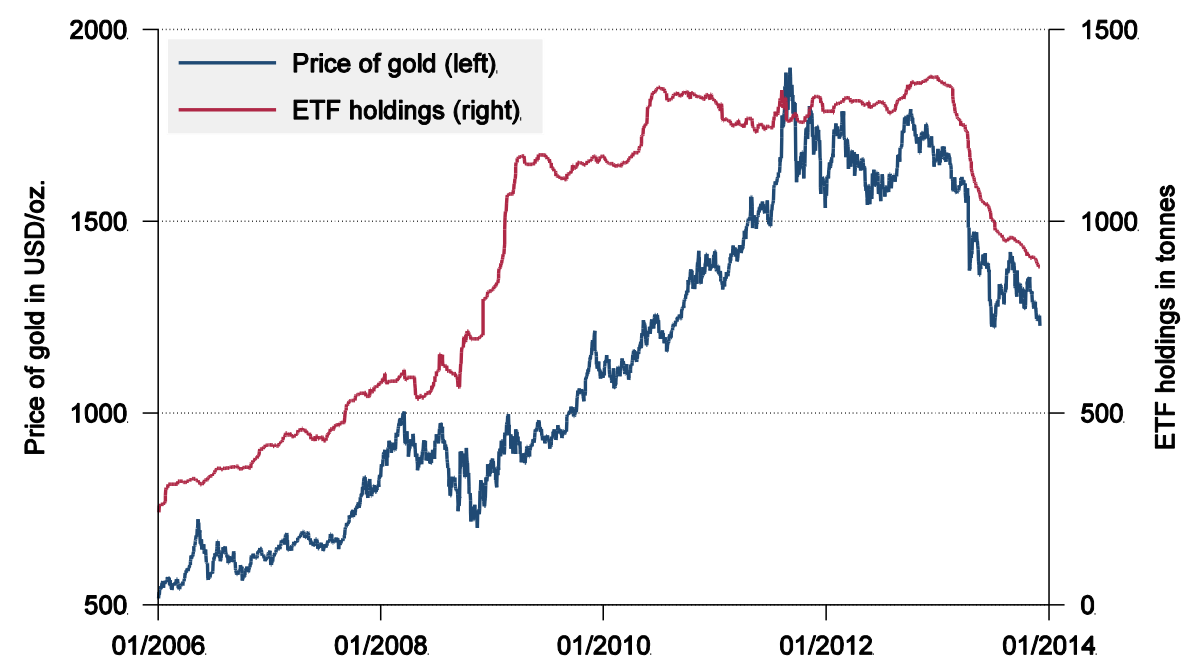

Figure 6: Price of gold and ETF holdings since 2006

Source: Bloomberg

It is thus possible that the recent co-movement of gold ETF holdings and the price of gold may just be spurious correlation. When one looks at the development of ETF holdings in physical silver ETFs it becomes more evident that this might indeed be the case. In Figure 7 we show the price of silver together with the holdings of the biggest physical silver ETFs since 2006. The correlation between changes in the price of silver and changes in ETF holdings are almost exactly zero no matter which time horizon we investigated. The biggest paradox, however, is that while silver has declined more than gold in 2013, holdings of silver ETFs have increased. It is extremely hard to explain why declining ETF holdings in gold should have driven prices lower but rising ETF holdings in silver could not prevent an even steeper drop in silver prices. 


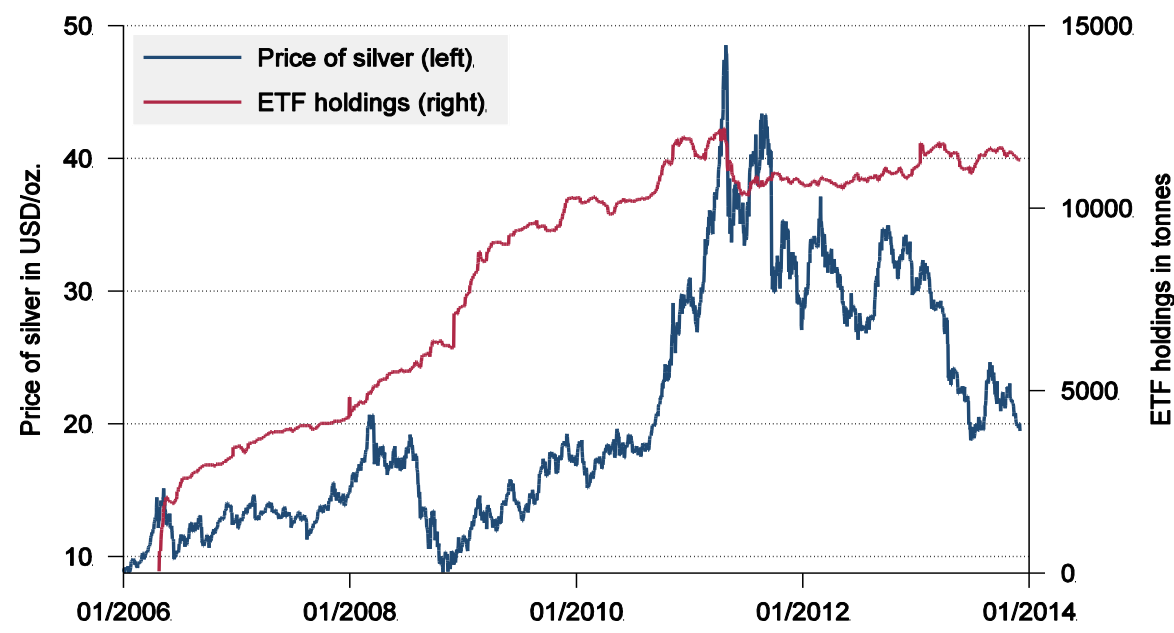

Figure 7: Price of silver and ETF holdings since 2006

Source: Bloomberg, Wellershoff \& Partners

One possible argument could be that physical gold ETFs are just a bigger share of total gold demand than silver ETFs of total silver demand. In this case the developments in silver ETFs would not be significant enough to materially impact silver prices. In order to directly test the theory that changes in ETF holdings impacted the price of gold in 2013 we have calculated cross-correlations between changes in the price of gold and changes in gold ETF holdings for the calendar year 2013 when the co-movement was strongest. Figure 8 shows the cross-correlogramm for different leads and lags of changes in the price of gold and changes in ETF holdings. It is clear, that changes in ETF holdings typically lag changes in the price of gold by about 1 to 10 days. On the other hand the correlation between changes in ETF holdings and subsequent changes in the price of gold disappears rather quickly. Put simply, what happens is that the price of gold drops and in the subsequent 5 to 10 trading days investors start selling their ETF holdings. Thus, using ETF holdings as a risk management tool in our view is highly unreliable because it reverses the causality of the relationship between the price of gold and investor behavior. 


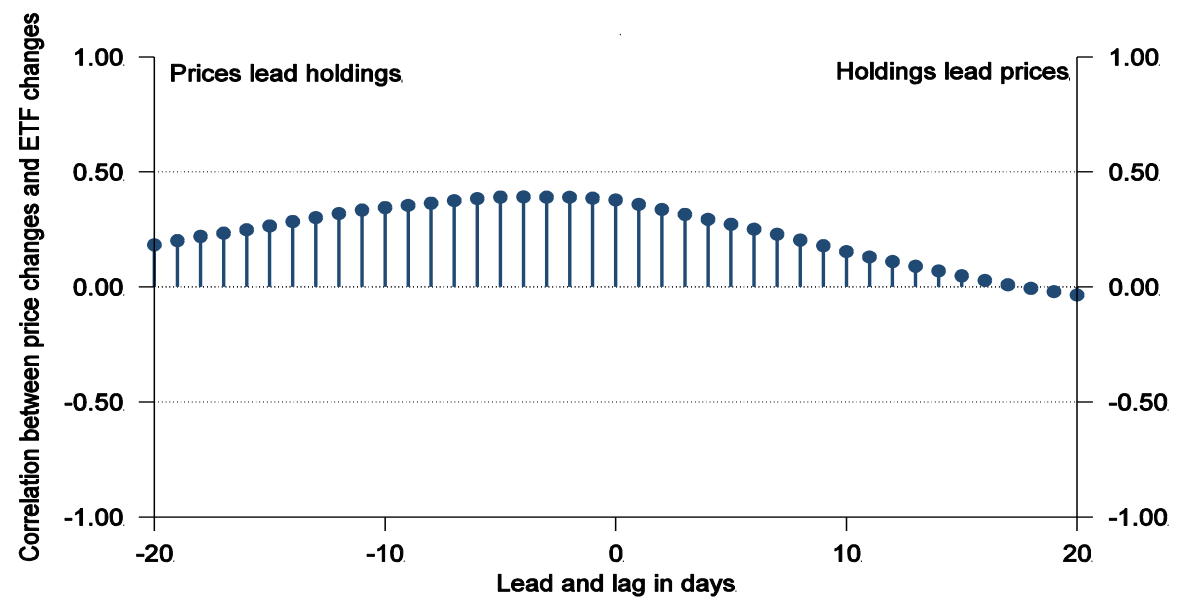

Figure 8: Cross-correlogramm of changes in the price of gold and changes in ETF holdings

\section{Conclusion}

We have investigated some factors that have been proposed as a driver of the price of gold. These factors can be used to develop effective risk management tools for gold investments if there is a stable and reliable relationship between them and the price of gold.

We have found that there are several factors that are supposedly influencing the price of gold but that show no discernible or stable relationship over time. In particular the relationship between the price of gold and the US Dollar exchange rate to other currency is weak and unreliable. Similarly there is no stable relationship between the price of gold and fund flow in or out of physical gold ETF. Even during the most recent time period of high correlation between the price of gold and gold ETF fund flows fund flows typically react with a delay of several days to changes in the price of gold rather than the other way round.

Similarly, the negative relationship between gold and equity markets in times of severe equity market stress might have declined in recent years because gold has become more popular as a crisis hedge amongst investors.

Our investigation indicates that the most reliable relationship exists between gold and strong increases in inflation. Strong increases in inflation rates are typically accompanied by strong increases in the price of gold, while moderate increases in inflation or declining inflation does not materially impact the price of gold in either direction. Another reasonably stable relationship exists between the marginal cost of production for an ounce of gold and the price of gold. The marginal cost of production acts as an effective floor for the price of gold over investment horizons of one to three years and thus can be exploited as a long-term risk management tool.

Overall, however, the drivers of the price of gold in the short run remain elusive and highly volatile. The result is that gold as an investment poses a significant challenge for risk managers and warrants further research in this field. 


\section{References}

Abdullah, A. (2013) Examining the Value of Money in England over the Long Term (1259 - 2009), International Journal of Economic and Finance, Vol. 5 (3), 73 - 89.

Baur, D. G. and B. M. Lucey (2010) Is Gold a Hedge or a Safe Haven? An Analysis of Stocks, Bonds and Gold, Financial Review, vol. 45 (2), 217 - 229.

Baur, D. G. and K. Glover (2012) The Destruction of a Safe Haven Asset?, University of Technology Sydney Working Paper No. 174.

Baur, D. G. and T. K. McDermott (2010) Is Gold a Safe Haven? International Evidence, Journal of Banking and Finance, vol. 34 (8), 1886 - 1898.

Erb, C. B. and C. R. Harvey (2013) The Golden Dilemma, Financial Analyst Journal, 69(4), $10-42$.

Jastram, R. W. (1977) The Golden Constant, The English and American Experience 1560 - 1976, John Wiley \& Sons, New York.

Korda Mentha (2013) Gold Ore Mining - All that Glitters is Not Gold, Publication No. $13-04$. 